\title{
Compressive behaviour of steel tubes filled with strain hardening cementitious composites
}

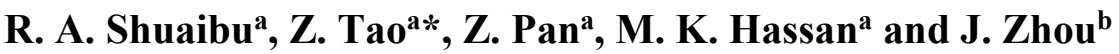 \\ ${ }^{a}$ Centre for Infrastructure Engineering, Western Sydney University, Penrith, NSW 2751, Australia \\ ${ }^{b}$ School of Civil and Transportation Engineering, Hebei University of Technology, Tianjin 300401, \\ China \\ *corresponding author, e-mail address: z.tao@westernsydney.edu.au
}

\begin{abstract}
This paper presents the compressive behaviour of steel tubes filled with strain hardening cementitious composites (SHCC) through experimental and numerical investigations. The main parameters considered in the experimental study include type (SHCC and normal concrete) and strength (normal and high strength) of the infill material, steel tube thickness ( 2 and $4 \mathrm{~mm}$ ) and cross-section type (circular and square). To develop the SHCC material, $2 \%$ of polyvinyl alcohol fibres by volume were used. The test results indicate that the performance of SHCC-filled steel tubes is generally similar to that of the counterparts filled with normal concrete. A finite element (FE) model was then developed to predict the load-deformation curves of the test specimens. In general, a reasonably good match is obtained between the predicted and measured curves.
\end{abstract}

Keywords: Concrete-filled steel tubular columns; strain hardening cementitious composites; normal concrete; compressive behaviour.

\section{Introduction}

Concrete-filled steel tubular (CFST) columns have been widely used in small to large scale infrastructure in many parts of the world [1]. This is because of the advantages resulting from the composite action between the steel tube and in-fill concrete in such columns. The in-fill concrete is passively confined by the steel tube, which leads to an increase in the concrete strength and ductility. Meanwhile, the inward buckling of the steel tube is prevented by the concrete restraint.

For CFST columns under axial or eccentric compression, the in-fill material contributes significantly to the stiffness, strength and deformation capacity of the columns [1-2]. Concretes made with different types of aggregates, such as steel slag, waste glass and lightweight aggregate, have been used by $\mathrm{Yu}$ et al. [2] to fabricate CFST columns. It was found that the performance of the composite column might be improved in some way when a certain type of aggregate is used. For example, the use of steel slag and waste glass has a potential to improve the fire resistance of the composite column [2]. This motivates the authors to explore the use of new in-fill materials, such as strain hardening cementitious composites (SHCC).

SHCC is a special class of cement composites that exhibit strength increase after the first crack by demonstrating multiplecracking behaviour under tension or bending loads. In the past few decades, different types of SHCC have been developed using different cementitious materials, fine sand, and about $2 \%$ volume of various polymer fibres. These materials are characterised by high tensile ductility of $3-7 \%$, in the order of about 300-700 times that of normal concrete under uni-axial tension [3]. Results have also shown that SHCC has a higher peak strain and better ductility under compression compared with normal concrete [4]. Although extensive studies on the material behaviour of SHCC have been conducted in the past, little information is available on the behaviour of CFST columns manufactured with SHCC.

To address the above research gaps, this study focuses on the compressive behaviour of 
steel tubes filled with normal or high strength SHCC. The behaviour of the SHCC-filled steel columns will be compared with that of conventional CFST columns. Furthermore, a finite element (FE) model will be developed to predict the load-deformation curves of the test specimens.

\section{Experimental program}

\subsection{Material properties}

Two categories of in-fill materials were used in this research. The first series contained SHCC with two different strengths (normal and high), whilst the other series contained normal concrete in the same manner. Mix proportions of the in-fill materials and the slump values are given in Table 1. SHCC mixes were made with $2 \%$ volume of oil coated polyvinyl alcohol (PVA) fibres from Kuraray Co. Ltd., Japan. The PVA fibres were $6 \mathrm{~mm}$ long with diameter, tensile strength, elastic modulus, and elongation of $26 \mu \mathrm{m}, 1600 \mathrm{MPa}, 39 \mathrm{GPa}$, and $6.2 \%$, respectively.

A total of sixteen CFST columns were prepared and tested at the Structures Laboratory of the Centre for Infrastructure Engineering, Western Sydney University. Eight of them were fabricated using SHCC, whilst the remaining eight were manufactured with normal concrete. A conventional concrete mixer was used to make the normal concrete, whereas a 56L pan type mortar mixer was used to make the SHCC. The SHCC mixes contained only fine silica sand with a maximum aggregate size of $600 \mu \mathrm{m}$. High range water reducer (HRWR) with a trade name of MasterGlenium SKY 8100, supplied by BASF Chemical Company, Australia, was used to adjust the workability of all the mixes as shown in Table 1.

The workability of conventional concrete was measured in terms of slump in accordance to AS1012.3, whilst that of SHCC was measured using the mini-slump also known as flow test similar to the one used by Yang et al. [5]. After the slump was measured, the fresh mixes were cast firstly into the hollow tubes and then into cylindrical moulds of size $\varnothing 100$ $\times 200 \mathrm{~mm}$ to measure the compressive properties at designated ages. For SHCC, additional coupon samples were prepared to measure the tensile stress-strain curves based on the direct tensile tests.

The specimen details and coupon tests were set up based on the recommendations made by the Japanese Society of Civil Engineers for testing high-performance fibre reinforced cementitious composites with multiple cracks [6]. Tables 2 and 3 provide the detailed material properties for the in-fill materials and steel, respectively.

Table 1. Concrete mix proportions.

\begin{tabular}{|c|c|c|c|c|c|c|c|c|c|c|c|}
\hline \multirow{3}{*}{ Mix } & \multicolumn{3}{|c|}{$\begin{array}{c}\text { Cementitious material } \\
(\mathrm{kg})\end{array}$} & \multicolumn{4}{|c|}{ Coarse and fine aggregate (kg) } & \multirow[t]{3}{*}{$\begin{array}{c}\text { Water } \\
\text { (kg) }\end{array}$} & \multirow[t]{3}{*}{$\begin{array}{c}\text { HRWR } \\
\text { (kg) }\end{array}$} & \multirow[t]{3}{*}{$\begin{array}{c}\text { PVA } \\
\text { (kg) }\end{array}$} & \multirow[t]{3}{*}{$\begin{array}{c}\text { Slump } \\
(\mathrm{mm})\end{array}$} \\
\hline & \multirow[b]{2}{*}{ Cement } & \multirow[b]{2}{*}{$\begin{array}{l}\text { Fly } \\
\text { ash }\end{array}$} & \multirow[b]{2}{*}{$\begin{array}{l}\text { Silica } \\
\text { fume }\end{array}$} & \multicolumn{2}{|c|}{ Limestone } & \multicolumn{2}{|c|}{ Sand } & & & & \\
\hline & & & & $\begin{array}{c}\mathbf{2 0} \\
\mathbf{m m}\end{array}$ & $\begin{array}{c}10 \\
\mathbf{m m}\end{array}$ & $\begin{array}{l}\text { River } \\
\text { sand }\end{array}$ & $\begin{array}{l}\text { Silica } \\
\text { sand }\end{array}$ & & & & \\
\hline $\mathrm{NC} 1$ & 380 & - & - & 484 & 592 & 667 & - & 189 & 1.62 & - & $235^{\mathrm{a}}$ \\
\hline $\mathrm{NC} 2$ & 585 & - & 59 & 472 & 577 & 609 & - & 168 & 5.00 & - & $28^{\mathrm{a}}$ \\
\hline SH1 & 412 & 824 & - & - & - & - & 456 & 285 & 5.10 & 26 & $225^{\mathrm{b}}$ \\
\hline $\mathrm{SH} 2$ & 574 & 227 & 238 & - & - & - & 952 & 237 & 18.10 & 26 & $98^{\mathrm{b}}$ \\
\hline
\end{tabular}

${ }^{\mathrm{a}}$ normal slump test; ${ }^{\mathrm{b}}$ mini flow test

Table 2. Concrete properties with age.

\begin{tabular}{|c|c|c|c|c|c|}
\hline \multirow{2}{*}{ Mix } & \multirow{2}{*}{$\begin{array}{c}\text { Air-dry density } \\
\left(\mathbf{k g} / \mathbf{m}^{3}\right) \\
\rho\end{array}$} & \multicolumn{2}{|c|}{ Compressive strength (MPa) } & \multirow{2}{*}{$\begin{array}{c}\text { Tensile strain } \\
(\%) \\
\varepsilon_{\mathrm{u}} \text { at } 28 \mathrm{~d}\end{array}$} & \multirow{2}{*}{$\begin{array}{c}\text { Tensile strength } \\
\text { (MPa) } \\
f_{\text {t.u at } 28 \mathrm{~d}}\end{array}$} \\
\hline & & $f^{\prime}$ at $7 \mathrm{~d}$ & $f_{c}^{\prime}$ at $28 \mathrm{~d}$ & & \\
\hline $\mathrm{NC} 1$ & 2375 & $30.2 \pm 1.3$ & $36.7 \pm 0.2$ & - & - \\
\hline $\mathrm{NC} 2$ & 2405 & $52.8 \pm 4.7$ & $77.3 \pm 0.9$ & - & - \\
\hline SH1 & 2009 & $35.4 \pm 0.8$ & $47.1 \pm 0.4$ & $3.4 \pm 0.2$ & $4.8 \pm 0.3$ \\
\hline $\mathrm{SH} 2$ & 2044 & $62.8 \pm 2.2$ & $81.9 \pm 2.0$ & $1.3 \pm 0.1$ & $3.8 \pm 0.2$ \\
\hline
\end{tabular}


Table 3. Steel properties.

\begin{tabular}{lccc}
\hline Section type & $\begin{array}{c}\boldsymbol{E}_{\mathbf{s}} \\
(\mathbf{G P a})\end{array}$ & $\begin{array}{c}\boldsymbol{f}_{\mathbf{y}} \\
(\mathbf{M P a})\end{array}$ & $\begin{array}{c}\boldsymbol{f}_{\mathbf{u}} \\
(\mathbf{M P a})\end{array}$ \\
\hline Circular tube $(2 \mathrm{~mm})$ & 216 & 314 & 369 \\
Circular tube (4 mm) & 229 & 318 & 389 \\
Square tube (2 mm) & 219 & 317 & 374 \\
Square tube (4 mm) & 221 & 324 & 410 \\
\hline
\end{tabular}

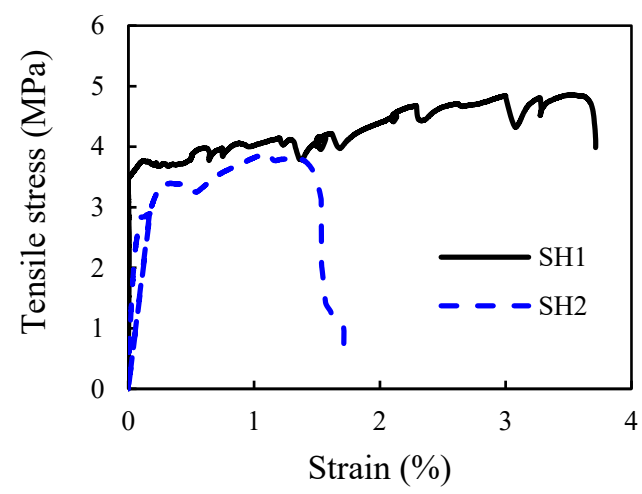

Fig. 1. Tensile stress-strain curves of SHCC.

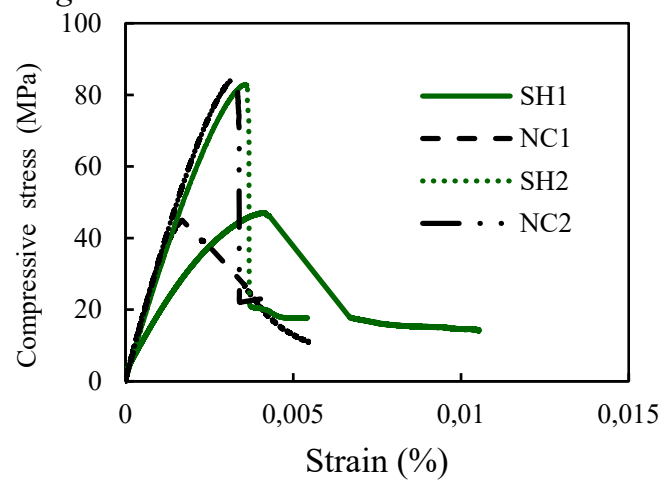

Fig. 2. Compressive stress-strain curves of normal concrete (NC) and SHCC (SH).
The tensile stress-strain curves of the SHCCs are shown in Fig. 1. The tensile strain of mix SH2 (1.3\%) decreases to $38 \%$ that of mix SH1 (3.4\%) when the compressive strength increases from 47.1 to $81.9 \mathrm{MPa}$ at 28 d. However, the tensile strength of $\mathrm{SH} 2$ is even smaller than that of SH1. The compressive stress-strain curves of the SHCCs are compared with those of normal concrete in Fig. 2. When the strength is relatively low, SHCC has a larger peak strain than the concrete. However, the difference between the high strength SHCC and concrete is not significant.

\subsection{Specimen preparation}

Table 4 summarises the information of the fabricated columns. Out of the 16 columns, eight were circular columns and the other eight were square columns. The specimens were designated as Q-X-YYN, where "Q" represents the shape of the tube ("C" for circular section and "S" for square section). The next letter " $X$ " represents the tube thickness, which is either 2 or $4 \mathrm{~mm}$. "YY" and " $\mathrm{N}$ " represent the type of the in-fill material: "SH" for SHCC and "NC" for normal concrete, respectively; and " $\mathrm{N}$ " is assigned a number 1 or 2 representing normal or high strength, respectively. The nominal diameter of the circular columns and the nominal width of the square columns are the same $(150 \mathrm{~mm})$.

Table 4. Details of test specimens.

\begin{tabular}{|c|c|c|c|c|c|c|c|c|c|}
\hline $\begin{array}{l}\text { Section } \\
\text { type }\end{array}$ & $\begin{array}{c}\text { Specimen } \\
\text { designation }\end{array}$ & $\begin{array}{c}B \\
(\mathrm{~mm})\end{array}$ & $\begin{array}{c}D \\
(\mathrm{~mm})\end{array}$ & $\begin{array}{c}t \\
(\mathrm{~mm})\end{array}$ & $D / t$ & $\begin{array}{l}\text { Mix } \\
\text { type }\end{array}$ & $\begin{array}{c}f_{\mathrm{c}^{\prime}} \\
(\mathrm{MPa})\end{array}$ & $\begin{array}{l}N_{\text {ue }} \\
(\mathbf{k N})\end{array}$ & $\begin{array}{l}\text { Age } \\
\text { (d) }\end{array}$ \\
\hline \multirow[t]{8}{*}{ Circular } & C-2-SH1 & - & 150 & 2 & 75.0 & SH1 & 47.1 & 1117.8 & 28 \\
\hline & $\mathrm{C}-2-\mathrm{NC} 1$ & - & 150 & 2 & 75.0 & $\mathrm{NC} 1$ & 45.3 & 1187.3 & 42 \\
\hline & C-4-SH1 & - & 150 & 4 & 37.5 & SH1 & 47.1 & 1433.9 & 28 \\
\hline & C-4-NC1 & - & 150 & 4 & 37.5 & $\mathrm{NC} 1$ & 45.3 & 1607.4 & 42 \\
\hline & $\mathrm{C}-2-\mathrm{SH} 2$ & - & 150 & 2 & 75.0 & $\mathrm{SH} 2$ & 83.4 & 1763.9 & 29 \\
\hline & $\mathrm{C}-2-\mathrm{NC} 2$ & - & 150 & 2 & 75.0 & $\mathrm{NC} 2$ & 85.1 & 1725.0 & 76 \\
\hline & $\mathrm{C}-4-\mathrm{SH} 2$ & - & 150 & 4 & 37.5 & $\mathrm{SH} 2$ & 83.4 & 2139.5 & 29 \\
\hline & $\mathrm{C}-4-\mathrm{NC} 2$ & - & 150 & 4 & 37.5 & $\mathrm{NC2}$ & 85.1 & 2032.0 & 76 \\
\hline \multirow[t]{8}{*}{ Square } & S-2-SH1 & 150 & 150 & 2 & 75.0 & SH1 & 47.1 & 1309.0 & 28 \\
\hline & $\mathrm{S}-2-\mathrm{NC} 1$ & 150 & 150 & 2 & 75.0 & $\mathrm{NC} 1$ & 45.3 & 1400.3 & 42 \\
\hline & S-4-SH1 & 150 & 150 & 4 & 37.5 & SH1 & 47.1 & 1674.4 & 28 \\
\hline & S-4-NC1 & 150 & 150 & 4 & 37.5 & $\mathrm{NC} 1$ & 45.3 & 1702.4 & 42 \\
\hline & $\mathrm{S}-2-\mathrm{SH} 2$ & 150 & 150 & 2 & 75.0 & $\mathrm{SH} 2$ & 83.4 & 2227.6 & 29 \\
\hline & S-2-NC2 & 150 & 150 & 2 & 75.0 & NC2 & 85.1 & 2090.0 & 76 \\
\hline & S-4-SH2 & 150 & 150 & 4 & 37.5 & $\mathrm{SH} 2$ & 83.4 & 2605.6 & 29 \\
\hline & S-4-NC2 & 150 & 150 & 4 & 37.5 & $\mathrm{NC} 2$ & 85.1 & 2373.0 & 76 \\
\hline
\end{tabular}


To fabricate the tubes, two cold formed semi-circular mild steel sheets were welded together to form a circular tube. In the same way, double U-shaped mild steel channels were cold formed and welded together to produce a square tube. End plates of $10 \mathrm{~mm}$ thickness were welded at the top and the bottom of each tube and a hole on the top plate was cut to enable for concrete pouring. Before concrete was poured into the steel tube, the thickness of each tube was measured. It was found that the measured thicknesses were very close to the nominal values.

The concrete/SHCC was poured in the steel tube in layers and vibrated using an electric vibrator. Immediately after that, the specimens were wrapped by plastic sheets to avoid moisture loss and cured under laboratory conditions until the specimens were tested.

\subsection{Test setup and instrumentation}

All specimens were tested under axial compression using a universal testing machine of $5000 \mathrm{kN}$ capacity as shown in Fig. 3. Four lateral and four longitudinal strain gauges were attached to each specimen at mid-height to measure the strain developments at those locations. Four linear variable displacement transducers (LVDT) were used in each test, two of which were used to measure the vertical deformation and the other two to measure the lateral deformation of the specimen as the load was applied. Prior to testing, the top of each specimen was applied with a layer of plaster to obtain a flat surface to ensure uniform load application. All samples were loaded at a displacement rate of $0.4 \mathrm{~mm} / \mathrm{min}$ up to failure.

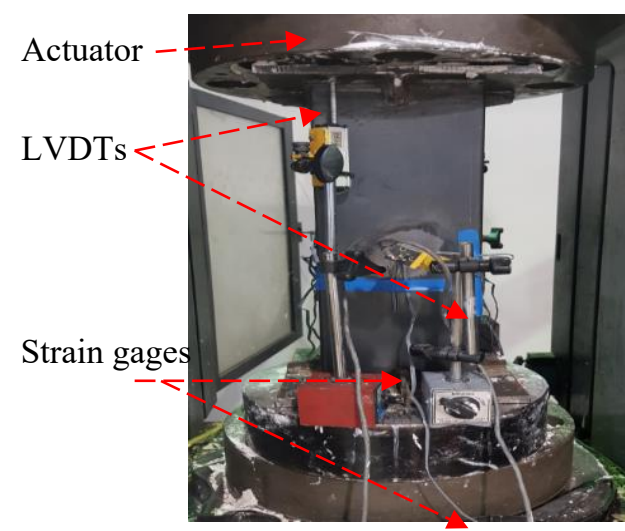

Fig. 3. Test setup.

\section{Experimental results and discussion}

\subsection{Failure pattern}

Fig. 4 shows the physical failure patterns of all the tested CFST columns. The columns with SHCC are shown in Fig. 4(a), whilst the corresponding CFST columns are shown in Fig. 4(b) in the same order for ease of comparison. Most of the specimens failed in a similar manner via outward buckling of the steel tube. However, the position and amplitude of the buckling differ in different specimens. For square columns, irrespective of the type of in-fill material, the specimens buckled at or near the mid-height position. On the other hand, all circular specimens except C4-SH1 buckled near the stiffeners at either the top or bottom of the specimen. C-4-SH1 also developed minor outward deformation near the ends. But the failure was mainly controlled by the severe local buckling occurred near the mid-height. In general, the failure modes of the current test specimens are similar to those reported in [2]. It seems the in-fill material has no significant influence on the failure mode of the composite column.

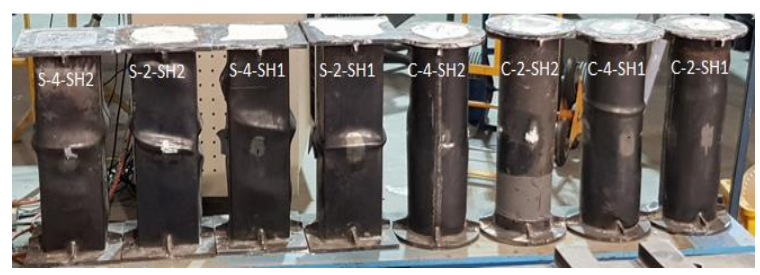

(a) Steel tubes filled with SHCC.

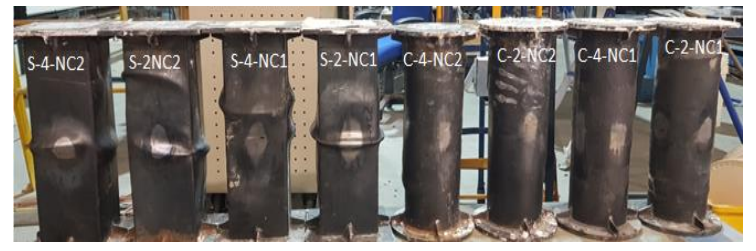

(b) Steel tubes filled with normal concrete.

Fig. 4. Failure pattern of tested columns.

\subsection{Axial load versus axial strain curves}

The axial load versus axial strain $(N-\varepsilon)$ curves shown in Figs. 5 and 6 are for circular and square columns, respectively. These curves were plotted based on the data collected from the strain gauges as well as the LVDTs. The strain readings of the four strain gauges were averaged and used to determine the $\varepsilon$-values before buckling. Afterwards, the axial deformation recorded by the LVDTs were 
averaged and divided by the length of the column to represent the axial strain. It seems that the in-fill material has no significant influence on the shape of the $N-\varepsilon$ curves when the compressive strengths of the SHCC and concrete are similar. The only exception is the obvious difference between the curves of $\mathrm{C}-2$ $\mathrm{SH} 1$ and $\mathrm{C}-2-\mathrm{NC} 1$, as shown in Fig. 5a.

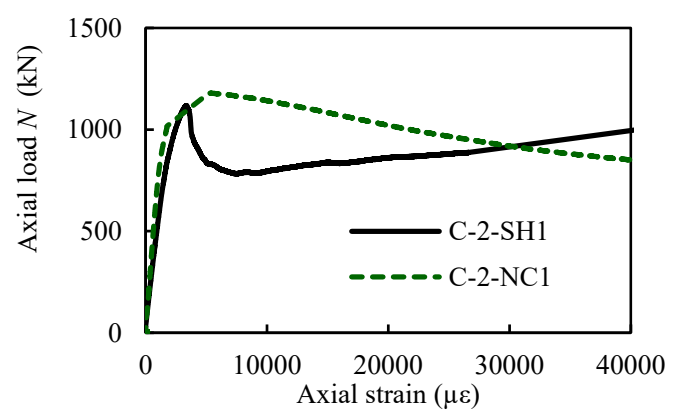

(a) Normal strength SHCC and concrete $(t=2 \mathrm{~mm})$.

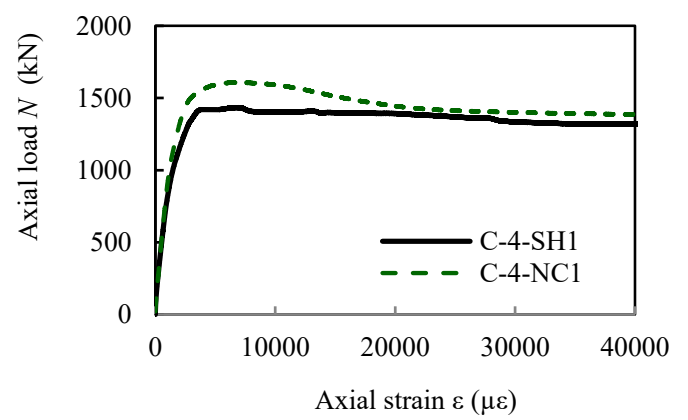

(b) Normal strength SHCC and concrete $(t=4 \mathrm{~mm})$.

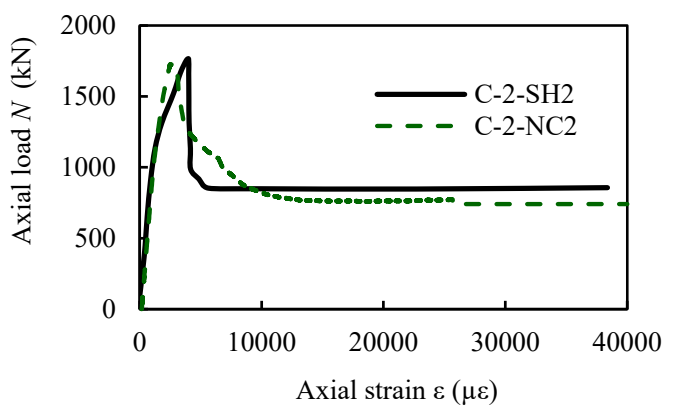

(c) High strength SHCC and concrete $(t=2 \mathrm{~mm})$.

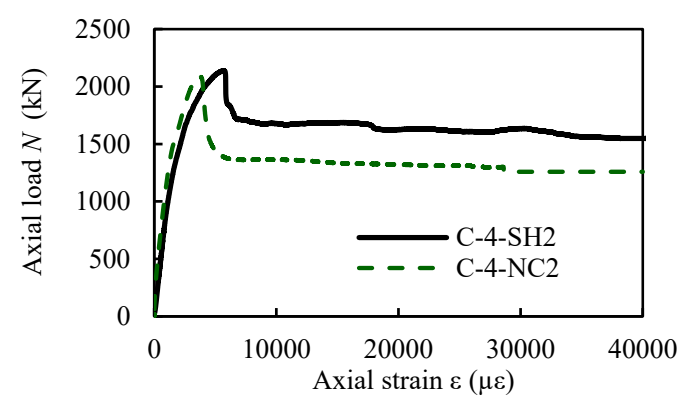

(d) High strength SHCC and concrete $(t=4 \mathrm{~mm})$

Fig. 5. $N-\varepsilon$ curves for circular columns.

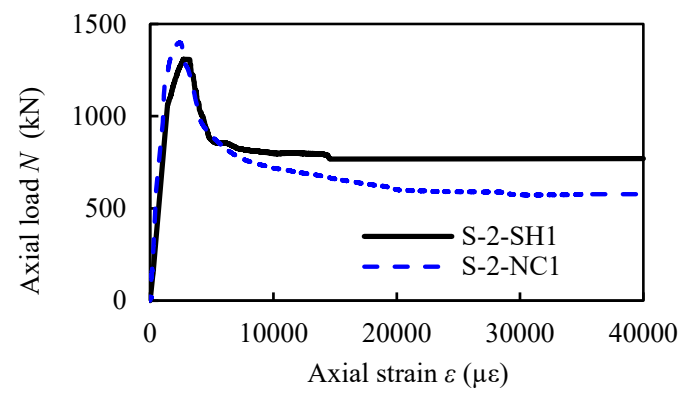

(a) Normal strength SHCC and concrete $(t=2 \mathrm{~mm})$.

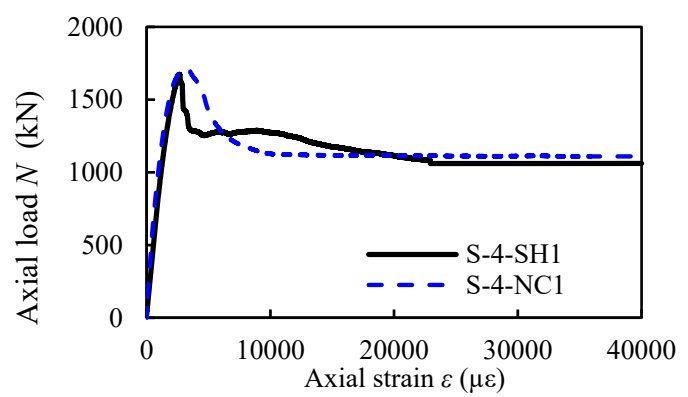

(b) Normal strength SHCC and concrete $(t=4 \mathrm{~mm})$

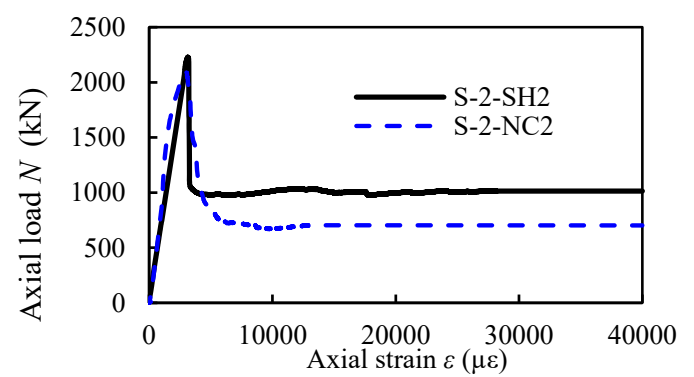

(c) High strength SHCC and concrete $(t=2 \mathrm{~mm})$

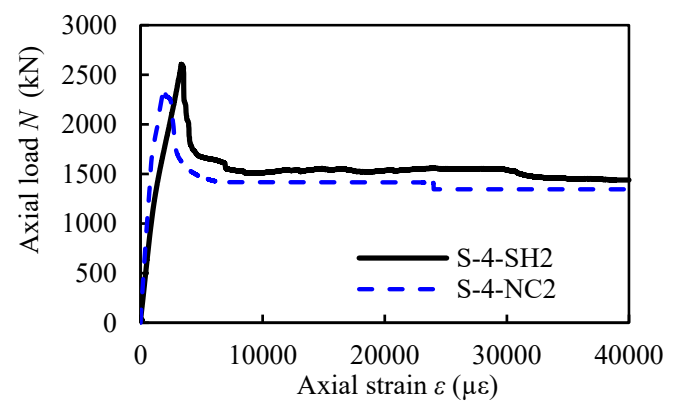

(d) High strength SHCC and concrete $(t=4 \mathrm{~mm})$

Fig. 6. $N-\varepsilon$ curves for square columns.

Compared with C-2-NC1 manufactured with normal concrete, specimen C-2-SH1 with SHCC exhibits a sudden failure after reaching the peak strength. This unexpected behaviour is probably due to test errors. Further research should be conducted to clarify this.

\subsection{Ductility}

Ductility refers to the capacity of CFST columns to undergo plastic deformation without any substantial reduction in strength. 
The ductility index $(D I)$ expressed by Eq. (1) is used in this paper to quantify ductility. This method has also been used by Yu et al. [2] for similar purposes.

$$
D I=\frac{\varepsilon_{90 \%}}{\varepsilon_{y}}
$$

where $\varepsilon_{90 \%}$ is the axial strain at a point on the descending portion of the curve when the strength decreases to $90 \%$ of its ultimate capacity, and $\varepsilon_{y}$ is expressed as $\varepsilon_{75 \%} / 0.75$ ( $\varepsilon_{75 \%}$ is the axial strain at a point on the ascending portion of the curve when the load reaches $75 \%$ of its ultimate capacity).

The ductility indexes of all the circular and square CFST columns are compared in Fig. 7. For the circular columns, the $D I$ values range from 1.50 to 4.40 , whilst the corresponding values range from 1.13 to 2.41 for square columns. It should be noted that the ductility of C-4-SH1 cannot be evaluated using Eq. (1) as the load of this specimen did not drop to $90 \%$ of its ultimate capacity because of negligible strength deterioration. Therefore, the ductility index of this specimen is taken as infinity. As can be seen in Fig. 7, the ductility index increases with increasing tube thickness or decreasing strength of the in-filled material because of better confinement. For the same reason, circular columns have higher ductility indexes than their square counterparts.

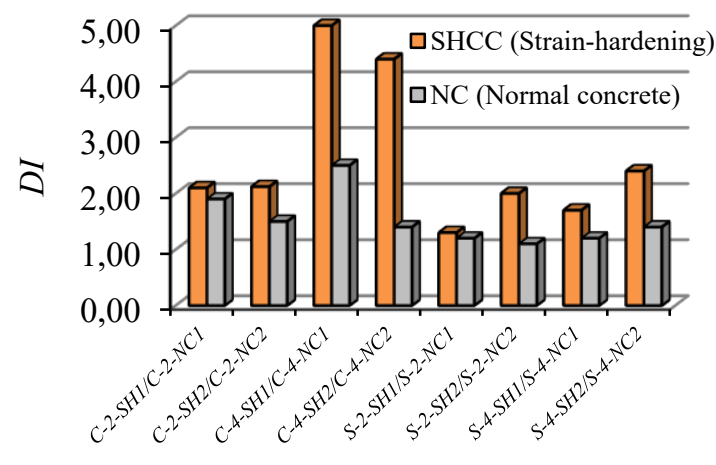

Specimen designation

Fig. 7. Ductility indexes $(D I)$ of test specimens.

The influence of the type of in-fill material on the ductility index can also be seen from Fig. 7. In general, SHCC-filled steel columns possess higher $D I$-values than those of normal CFST columns. This can be explained by the fact that SHCC has a larger peak strain than normal concrete, resulting in an increase in $\varepsilon_{90 \%}$.

\subsection{Ultimate Strength}

Strength index is used to measure the possible strength enhancement in the composite column resulted from the interaction between the steel tube and the in-fill material. The strength index is defined by Eq. (2) as the ratio of the ultimate strength of the composite column $\left(N_{\mathrm{ue}}\right)$ to the sum $\left(N_{0}\right)$ of individual strength contributions of the in-fill material and the steel tube.

$$
S I=\frac{N_{u e}}{N_{0}}
$$

The values of $S I$ for circular columns vary from 1.00 to 1.24 , whilst those for square columns vary from 0.95 to 1.07 .

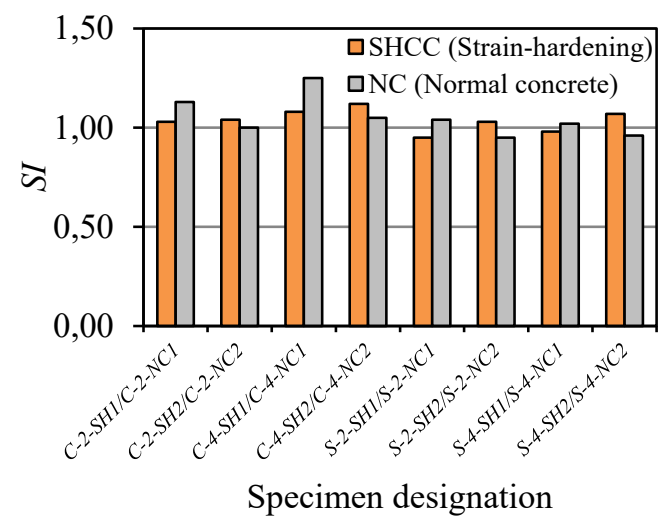

Fig. 8.Strength indexes $(S I)$ of test specimens.

In general, obvious strength enhancement is observed in all circular columns regardless of the tube thickness and the strength and type of the in-fill material. However, the SI-values of all square columns are close to unity, indicating relatively low confinement from the square tubes. This is consistent with previous research findings [1]. No obvious benefits are found in terms of strength enhancement when SHCC is used to fill the steel tube. Hoang and Fehling [7] conducted compression tests on 12 ultrahigh performance concrete (UHPC) columns confined by circular steel tubes. The UHPC was made by adding up to $2 \%$ by volume of micro steel fibres with a diameter of $0.175 \mathrm{~mm}$ and a length of $13 \mathrm{~mm}$ into the mix. Their test results indicate that the effect of steel fibres on the strength and ductility enhancement is also insignificant. Hoang and Fehling attributed this to the lower confinement effect induced by lower dilation of the UHPC with steel fibres. This mechanism might also be applicable to 
SHCC-filled steel tubes. Further research is required to clarify this finding.

\section{Comparison with FE predictions}

Tao et al. [8] developed a FE model that is capable of predicting the full-range load-deformation curves of CFST columns under axial compression. The simulation was based on concrete damaged plasticity material model in ABAQUS. The FE model developed by Tao et al. [8] is tentatively used in this study to predict the load-deformation curves of SHCC-filled steel columns. No modifications were made to the concrete model.
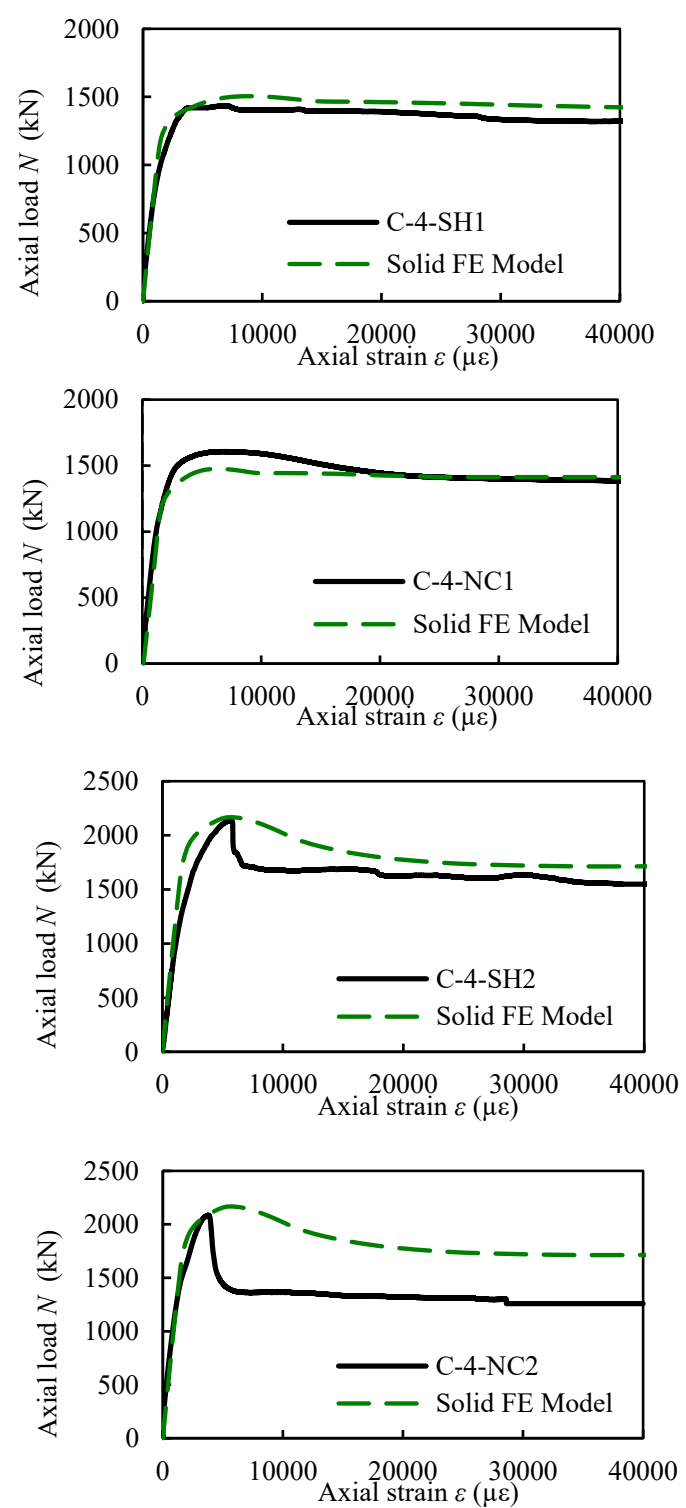

Fig. 9. Test and FE predicted results for circular CFST columns.

More details can be found in [8] about the element types, boundary conditions, material models and the interface parameters between the steel and in-fill material.

Figs. 9 and 10 compare the FE predictions with measured $N-\varepsilon$ curves for typical circular and square specimens, respectively. In general, the ultimate strength is predicted reasonably well. The ratios of experimental to predicted ultimate strength range from 0.95 to 1.05 for the circular columns and from 0.98 to 1.07 for the square columns.
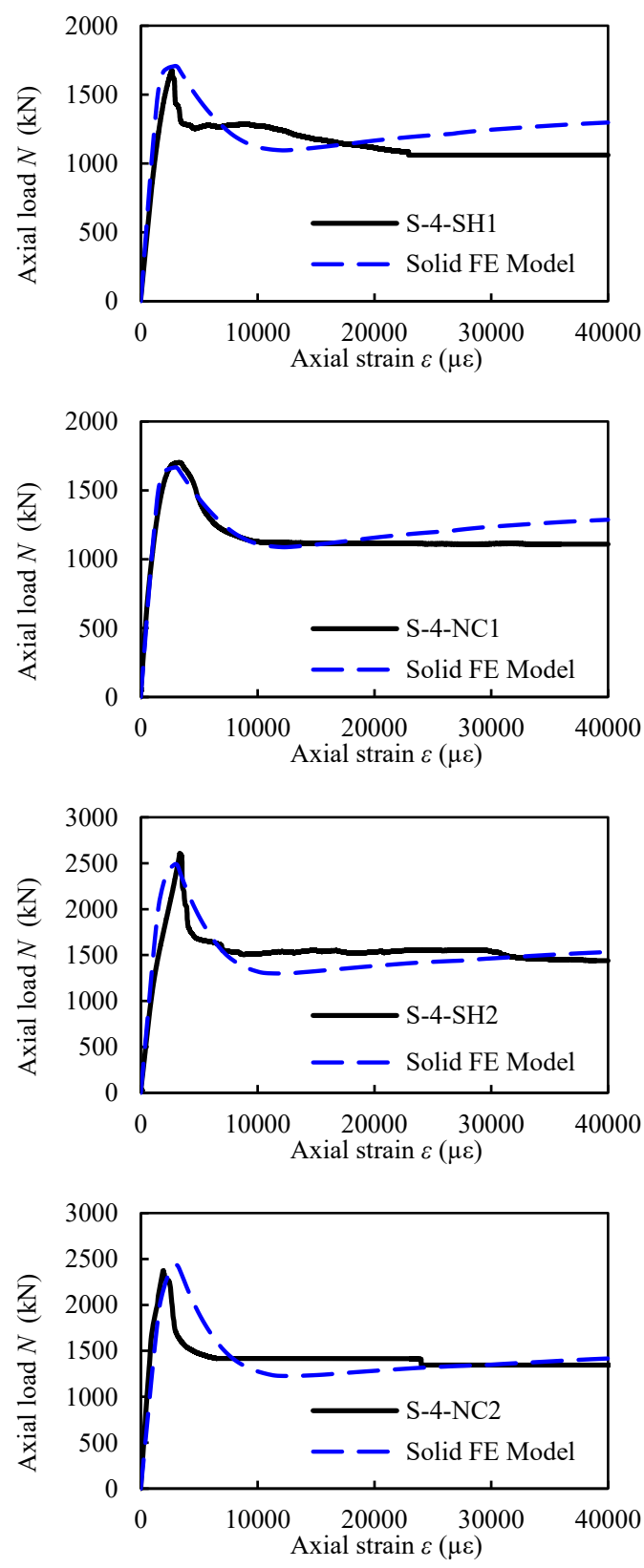

Fig. 10. Test and FE predicted results for square CFST columns.

It is also found from Figs. 9 and 10 that the agreement between the predicted and measured $N-\varepsilon$ curves are generally reasonable except that the measured curves of specimens C-2- 
SH1, C-4-SH2 and C-4-NC2 have a sharp strength decrease after reaching the peak load. This is not well captured in the simulation. It seems that reasonable accuracy can still be achieved if the FE model developed by Tao et al. [8] for conventional CFST columns is used to simulate SHCC-filled steel columns under axial compression. Suitable modifications could be made to the FE model once more test results of SHCC-filled steel columns are available.

\section{Conclusions}

Experimental and numerical investigations have been conducted to investigate the compressive behaviour of steel tubes filled with strain hardening cementitious composites (SHCC). The following conclusions can be drawn from this research work:

(1) SHCC-filled steel columns have similar failure modes as conventional concrete-filled steel tubular (CFST) columns. All square specimens buckled at or near the mid-height, whilst all circular specimens except one specimen buckled near the ends of the specimens.

(2) The in-fill material has no significant influence on the shape of the axial load versus axial strain $(N-\varepsilon)$ curves when the compressive strengths of the SHCC and concrete are similar.

(3) In general, SHCC-filled steel columns possess higher ductility indexes than those of normal CFST columns. This is because SHCC has lower elastic modulus but a larger peak strain than normal concrete.

(4) No obvious benefits have been found in terms of strength enhancement when SHCC is used to fill the steel tube. This may be explained by the lower dilation of the SHCC with PVC fibres. Material tests need to be conducted to measure the Poisson's ratio of the SHCC.

(5) Reasonable accuracy has been achieved when the FE model developed by Tao et al. [8] for conventional CFST columns is used to simulate SHCC-filled steel columns under axial compression. This FE model may be modified in the future to improve prediction accuracy once more test results of SHCC-filled steel columns are available.

\section{Acknowledgements}

The fist author would like to appreciate the liberality of Australian government and Western Sydney University for providing him a $\mathrm{PhD}$ scholarship, without which this research would not have been possible. The authors also want to acknowledge the assistance from the Project Manager, Mr. Robert Marshall and other Technical Officers at the Centre for Infrastructure Engineering Laboratory, Western Sydney University.

\section{References}

[1] Han LH, Li W, Bjorhov R. Development and advanced applications of concrete-filled steel tubular columns (CFST) structures. Journal of constructional steel research 2014; 100: 211228.

[2] Yu X, Tao Z, Song TY. Effect of different types of aggregates on the performance of concrete-filled steel tubular stub columns. Materials and Structures 2016; 49: 3591-3605.

[3] Kanda T, Li VC. New micromechanics design for pseudo-strain hardening cementitious composites. ASCE Journal of Engineering Mechanics 1999; 125(4): 373-381

[4] Ding Y, Yu JT, Yu KQ, Xu SL. Basic mechanical properties of ultra-high ductility cementitious composites: From $40 \mathrm{MPa}$ to 120 MPa. Composite Structures 2018; 185: 634645.

[5] Yang EH, Sahmaran M, Yang Y, Li VC. Rheological control in production of engineered cementitious composites. ACI Material Journal 2009; 106(4): 357-366

[6] Japanese Society of Civil Engineers. Recommendations for design and construction of high performance fibre reinforced cement composite with multiple cracks (HPFRCC). Concrete engineering series $2008 ; 82$.

[7] Hoang AL, Fehling E. Effect of steel fiber on the behaviour of circular steel tube confined UHPC columns under axial loading. International Conference on Strain-Hardening Cement-Based Composites 2017; Springer, Dordrecht, 482-491.

[8] Tao Z, Wang ZB, Yu Q. Finite element modelling of concrete filled steel stub column under axial compression. Journal of constructional steel research 2013; 89: 121131. 